\title{
Post-Mortem Investigation Through Virtual Autopsy Techniques: Proposal of a New Diagnostic Approach to Reduce the Risks of Operators During Emergencies
}

\author{
Andrea Malizia ${ }^{1 *}$, Laura Filograna ${ }^{2}$, Colleen Patricia Ryan ${ }^{3}$, Guglielmo Manenti $^{1}$ \\ ${ }^{1}$ Department of Biomedicine and Prevention, University of Rome Tor Vergata, Via di Montpellier 1, 00133 Rome, Italy \\ ${ }^{2}$ Policlinico Tor Vergata: Fondazione PTV, Via di Motpellier 1, 00133 Rome, Italy \\ ${ }^{3}$ University of Rome Tor Vergata, Via di Montpellier 1, 00133 Rome, Italy
}

Corresponding Author Email: malizia@ing.uniroma2.it

https://doi.org/10.18280/ijsse.100413

Received: 10 July 2020

Accepted: 22 August 2020

\section{Keywords:}

emergency, SARS-COV-2, virtual autopsy, post-mortem, investigation, risk, pandemic

\begin{abstract}
Natural outbreaks of biological agents, causing local and global emergencies, have impacted human safety, social/political/economical activities, and the security of critical infrastructures. Lessons learned by previous emergencies have been used by decisionmakers not only to improve the phases of prevention, intervention, and recovery of normality but also to facilitate the dual-use of methods, instruments, and technologies. A crucial phase of emergency management is the investigation that in the past was based on questioning, suspicions, witnesses, and often unreliable evidence. Nowadays investigation is supported by technology and various types of forensics that are deeply involved. The authors in this paper consider the pandemic outbreak of SARS-COV-2 as a case study and propose virtual autopsy by postmortem CT (PMCT) as a technique to facilitate post-mortem examinations on ascertained or suspected SARS-COV-2 cases. This method reduces the risk of infection for the operators that have to conduct the particular investigations during the emergencies.
\end{abstract}

\section{INTRODUCTION}

The global spread of biological agents along with loss of national control have been long-standing concerns in the post-Cold War world. In recent years, the fear that new epidemic situations could degenerate into a pandemic has been alive since the early years of the new millennium with the first SARS epidemic that provoked the "bird flu", the MERS epidemic, the Swine flu and the recent outbreaks of Ebola. The SARS-COV-2 epidemic has been the worst epidemic emergency since the Spanish Flue [1, 2] and is forcing the world to push knowledge over new boundaries. This has led to the invention of new vaccines and drugs and integrating existing technologies and methods or using them in an innovative way (such as the dual-use approach) to face emergency situations.

The national security strategies of each country place a strong emphasis on these matters through multidisciplinary research, focused on the long-term perspective, that plays an important role in understanding the implications of constant rapidly changing technological development in the area of pandemic emergencies. It will also allow enlightening as to how the global spread of scientific education might affect aspirations of different states to use these technologies and the knowledge to reduce the risks connected to operators directly involved in the emergencies. Because of safety and security budget reduction, how different countries prepare for pandemic emergencies deserves renewed attention; this involves the prioritization of capabilities in the Analysis, Prevention, and Response (APR) phases. It is also necessary to acquire detailed information about the capability of the states involved to use or produce certain technologies. The interactions between nations and experts in different disciplines is fundamental to acquire new types of capabilities and develop more effective policies.

In this context, the authors can ascertain that forensic science is like an umbrella that encompasses experts with different backgrounds using their skills to aid decisionmakers to solve a crime or to manage emergencies or crises. SARS-COV-2 has provoked millions of contagions and hundreds of thousands of victims in 2020 [1] with a huge impact on the community of health operators. Reducing the risks for health operators is essential to maintain the integrity of the National and International Systems and to save lives.

The autopsy of those who died because of COVID-19 has to be performed, for legal reasons, if the deceased person is part of a forensic investigation (the suspect of COVID-19 disease cannot be an obstacle in this case). The forensic pathologists working in the morgues have to follow the same indications and guidelines for the correct management of potentially infectious pathogens applied in clinical and research practice in microbiology laboratories because of the high infectivity of this particular virus.

In this particular context, the authors, propose modern techniques using virtual autopsy by PMCT and its subsidiary techniques (percutaneous biopsy, as a viable non-invasive, or minimally invasive technique) for analysis of suspected or confirmed SARS-COV-2 deaths to reduce the risk of infection for the operators and increase the quantity of data available to perform an effective investigation. 


\section{SARS-COV-2 AND AUTOPSY}

It is now well known that the SARS-COV-2 causes an illness in humans and has been named coronavirus disease 2019 (COVID-19) by the World Health Organization (WHO). This pathology attacks primarily the upper respiratory tract (Figure 1). In fact, the lungs represent the predominant site of entry and replication of SARS-COV-2, together with the endothelial cells and the kidney [3, 4].

It is not completely clear, at this stage, how the COVID-19 affects other organs even if a large amount of literature is now available on the clinical effects of this disease [5]. The present literature is quite poor regarding histopathological studies based on autopsy cases [6-8]. This is a key aspect to understand the pathophysiological mechanisms of SARSCOV-2, to improve the prevention and treatment of patients with COVID-19. The Health and Safety Executive's (HSE) Advisory Committee on Dangerous Pathogens (ACDP) [9] has defined four hazard groups, SARS-COV-2 is located in the pathogen category HG3 $[9,10]$. This is way, to reduce the risk of cross-contamination during and after post-mortem examinations, it is common practice of governments and health systems worldwide to restrict traditional autopsies as much as possible. The precautions indicated by the international health organizations [10-12] are related to the environment where the autopsy is performed (ventilation, temperature, pressure, humidity, and distances), the personal protective equipment (PPE) of the operators and the training/preparation of the operators. It is also necessary to prepare the room with the minimum equipment and consumables to perform the autopsy and collect the fluid samples (blood, urine, cerebrospinal) to minimize the risk of cross-contamination [12].

It is fundamental, to improve the investigation phase even in emergency situation, to guarantee carrying out of the autopsy and the safety of the medical operators. This is way the authors are to propose the Virtual autopsy for analysis of suspected or confirmed SARS-COV-2 deaths.

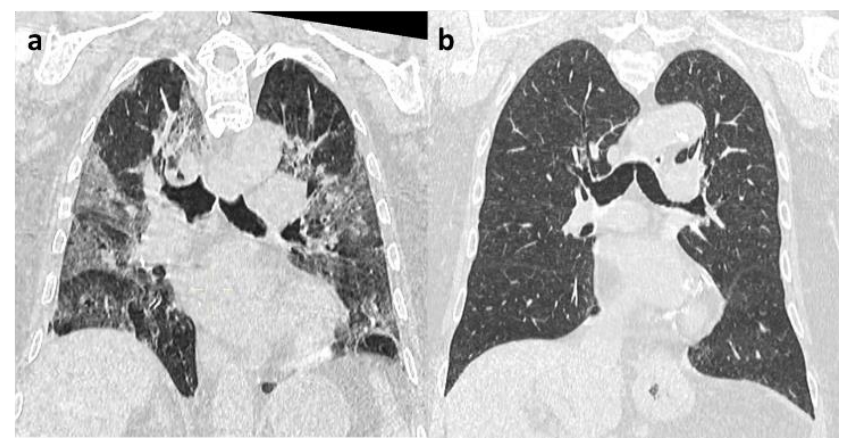

Figure 1. Coronal CT images at the level of the thorax (lung window level of the gray scale) in a patient massive pneumonia positive for SARS-COV-2 (a), and in a patient without pulmonary CT alterations (b).

Note in (a) multiple ground-glass opacities with septal thickening (crazy paving pattern) compatible with massive pulmonary involvement of COVID19. This image is from the database of the Policlinico di Tor Vergata that is the COVID Hospital 4 in the city of Rome, Italy.

\section{VIRTUAL AUTOPSY AS A NON/LOW-INVASIVE TECHNIQUE FOR POST-MORTEM ANALYSIS}

The term "Virtual autopsy" or "Virtopsy ${ }^{\circledR} "$ defines a set of imaging techniques used on a cadaver for forensic purposes
[13-15]. The techniques already applied for a non/lowinvasive autopsy to improve the forensic analysis are CT, MRI, photogrammetry and 3D surface scanning, PMCT angiography and percutaneous post-mortem biopsy (eventually under CT guide for tissue or body fluid sampling). However, the key to a modern virtual autopsy is a wholebody PMCT scan [16]. PMCT is used to analyze violent deaths because of its optimal visualization of skeletal traumatic lesions, intravascular gas, and foreign bodies (Figure 2).

This technique present limits in investigating "natural" deaths, because of the low sensitivity in differentiating soft tissue interfaces and reporting vascular alterations [15]. In 2005 PMCT angiography was introduced by Jackowski et al. [17] as a new supplementary technique to overcome the limits of classic PMCT. Since then, this innovative technique has improved [18-20] and other whole-body PMCT angiography techniques were implemented [21, 22], with differences in the intravascular contrast media and the contrast-media injection/propulsion methods. The absence of body samples for histopathological, microbiological, or toxicological analysis is a strong limitation in applying virtual autopsy even if implemented by PMCT angiography.

In 2007, the Swiss group of Thali [23-26] became a pioneer in the virtual autopsy field by demonstrating the effectiveness in combining PMCT virtual autopsy with postmortem percutaneous biopsy to provide specimens suitable for histological examination and reduce the invasiveness. The efficiency of these combined techniques is evident in terms of providing data (post-mortem gross pathological data, toxicological data, and microbiological data) to establish the modalities and causes of death with higher accuracy. PMCT and other post-mortem imaging techniques have also been successfully applied for non-forensic analysis like pathological and/or veterinary investigations [27-29].

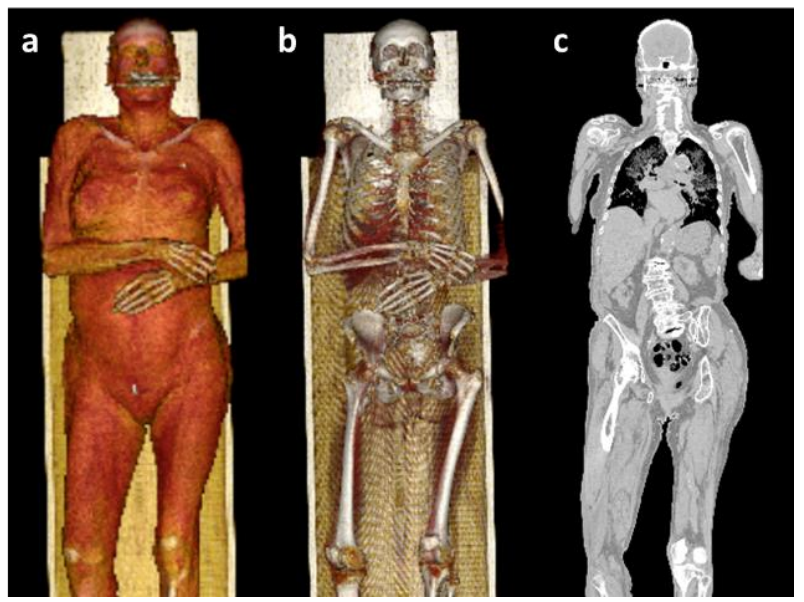

Figure 2. Virtual autopsy PMCT images in a fatal case of natural death (myocardial infarction)

Note the $3 \mathrm{D}$ volume rendering images ( $\mathrm{a}$ and $\mathrm{b}$ ) with anterior view the body lying on the CT bed, with soft tissue (a) and bone windowing (b). The coronal PMCT MPR reconstruction in (c) shows 2D anterior view of the same cadaver. The image is taken from the author's working database.

\section{VIRTUAL AUTOPSY TECHNIQUES IN POST- MORTEM INVESTIGATIONS ON SARS-COV-2 ASCERTAINED OR SUSPECTED CASES}

In biopsy and autopsy studies, pulmonary pathology for both early and late phase COVID-19 patients showed diffuse 
alveolar damage with the formation of hyaline membranes, mononuclear cells, and macrophages infiltrating air spaces, and diffuse thickening of the alveolar wall. Lung disease is the main manifestation of COVID-19 but a complete map of pathogenic mechanisms in SARS-COV 2 infection is still missing because of its capability to provoke multiple organ dysfunction $[7,8]$. Some of the most common pathological evidence in other organs reported in the literature are [30-34]: hilar lymph node necrosis, spleen atrophy, focal hemorrhage in the kidney, liver enlargement with inflammatory cell infiltration, gastrointestinal damage with diarrhea and acute abdomen, edema and scattered degeneration of the neurons in the brain.

\subsection{Potentials of a virtual autopsy in lung disease related to COVID-19}

Different CT patterns for lungs are suggested by clinical studies in the literature [35-40] together with cases that have an unclear or distribution of ground-glass opacities. Equally important is the similarity between the patterns identified in the lungs of the patients with COVID-19 compared to one of the patients affected by other viral pathogens (like virus Influenza A, or another source of lung pathology such as drug reaction). Therefore, CT is not usually suggested as a screening tool for the diagnosis or exclusion of COVID-19 in the clinical settings even if it is a valuable pre-test method due to its relatively high speed and sensitivity [41]. Moreover, some of the standard techniques like RT-PCR analysis on nasopharyngeal swabs may delay the diagnosis or even miss diagnose of SARS-COV-2 because of the potential presence of false negatives [42].

The potential of PMCT in detecting significant pulmonary alterations in post-mortem analysis is well known in literature [43]. The imaging of lungs in non-enhanced computed tomography (both in clinical and in post-mortem setting) allows the acquisition of high-quality data to thanks to the intrinsic contrast related to the presence of air. PMCT imaging of lungs, in cases of drowning and blood aspiration in thoracic trauma, is commonly used as a tool for forensic investigation and also applied as post mortem method in combination or substitution of autopsy [44]. The post mortem alteration of lungs [43], due to their structure complexity, may affect PMCT imaging results that might hide COVID-19 lung involvement. In theory, the probability that this occurrence happens is higher in the initial stages of lung pathology, when few and scanty areas of ground-glass opacity could be located in dorsal, peripheral regions, eventually in the inferior lobes, thus with the same distribution of internal livors. However, during the pandemic of SARS-COV-2, for a radiologist operator, the natural consequence of the evidence of pulmonary CT findings (typical for COVID-19) is to suggest the diagnosis of SARSCOV-2 infection in the lungs. Patients who died from SARSCOV-2 infection, as already shown in a case of the virtual autopsy by PMCT performed in Switzerland by the group of Thali [45], generally show a dramatic involvement of the lungs with an ARDS resemblance.

\subsection{Potentials of virtual autopsy findings in extra- pulmonary manifestations related to COVID-19}

SARS-COV-2 has demonstrated the capability to affect other organs through a direct attack or an indirect mechanism mediated by inflammation and coagulation mediators. The lymph nodes, heart, kidneys, spleen, liver, gastrointestinal tract, and brain are among the organs that can be affected by COVID-19 disease [30]. Uncommon manifestations have been reported in:

(1) The thorax where the mediastinal lymphadenopathy if found with lymph node enlargement that can be potentially detected by CT imaging suggesting expression of the inflammatory response to the infection [46-48].

(2) In the gastrointestinal tract where distended fluidfilled small and large bowel loops and surrounding stranding are demonstrated on enhanced CT [30].

SARS-COV-2 was also detected in the liver cells in some histopathological studies [49]. Micro-vesicular steatosis of a moderate entity and mild lobular and portal inflammatory activity was revealed in the liver histological analysis of SARS-COV-2 patients $[7,50]$. In literature, there is not CT imaging research related to these pathological alterations of the liver but these should be reflected in PMCT imaging by diffuse hypo-density of the liver due to unspecific steatosis [30]. SARS-COV-2 may provoke hemorrhagic lesions in the brain due to due to potential endothelium damage [51, 52]. Possible CT manifestations of SARS-COV-2 in the brain are hypo-density together with the bilateral medial thalami on the head CT and hemorrhagic lesions [52, 53].

The $71.4 \%$ of COVID-19 victims suffered from disseminated intravascular coagulation, with abnormal coagulation results in the later stages of the disease. It has been demonstrated that there is a link between increased concentrations of D-dimer and other fibrin degradation which leads to poor prognosis [54].

The literature suggests that COVID-19 patients in critical conditions are affected by two types of pathologic coagulation processes. The first is related to the microcirculation of the lungs and other organs causing the formation of microvascular clots [55]. The second is related to the systemic circulation with the potential development of large-vessel thrombosis and major thromboembolic events, including pulmonary embolism [56-58].

PMCT angiography has been introduced in the virtual autopsy as a complementary technique to add important information about the vascular bed in non-decomposed cadavers, enhancing possible applications of the virtual autopsy, particularly in natural deaths $[20,59]$. The literature reports both:

(1) The ability of PMCT angiography to document central and paracentral pulmonary thromboembolism [20, 59], with the complete concordance with autopsy results and histological analysis. Also, deep venous thrombosis has been demonstrated in some cases of PMCT angiography documented pulmonary embolism [59].

(2) The development of small post-mortem clots and/or the presence of possible small filling defects related to artifacts generally prevents the correct identification of peripheral pulmonary embolisms [20]. In the case of suspected lethal pulmonary embolisms, the accuracy of PMCT angiography diagnosis in detecting pulmonary embolism is not completely proven, due to the absence of robust statistics. Moreover, factors related to post-mortem clots and artifacts may compromise the accuracy of this post-mortem imaging technique in demonstrating pulmonary embolism. In these cases, a full autopsy dissection is mandatory. 
PMCT angiography might be proposed as a viable technique for detecting central and paracentral pulmonary embolism or other major thrombotic or thromboembolic phenomenon in the systemic circulation with reduced invasiveness in subjects deceased with COVID-19. It is important to point out that the combination with the histological analysis is highly recommended to improve the capability to demonstrate microvascular thrombosis and embolism. Post-mortem multi-organ percutaneous biopsy has already been applied to post-mortem investigations in three cases of deceased COVID-19 patients [34] in low invasive autopsy settings. Post-mortem percutaneous biopsies with PMCT guidance may represent a useful technique for low invasive post-mortem investigations in subjects deceased with ascertained or suspected SARS-COV-2 infection. In those cases, post-mortem percutaneous biopsies can overcome the above-mentioned limitations of the virtual autopsy with unenhanced PMCT or also with PMCT angiography, providing tissue and body fluid samples for histological, immunohistochemically, microbiological and toxicological analysis.

\section{ADVANTAGES OF THE VIRTUAL AUTOPSY IN ASCERTAINED OR SUSPECTED SARS-COV-2 INFECTED DEATHS}

SARS-COV 2 infection provokes a severe disease which has spread rapidly all over the world. The Italian National Institute of Health has underlined the importance of histopathological, microbiological, and virological analysis on tissue and biological specimen's analysis on deceased people with ascertained and suspected SARS-COV-2 infection during the post-mortem analysis. The purpose of the autopsy procedure on the COVID-19 ascertained cases is also to contribute to understanding the pathophysiological mechanisms of SARS-COV-2 to advance the prevention and treatment of patients. It has to be pointed out that Italian National Institute of Health and other health institutions worldwide have advocated the limitation of body dissections in ascertained and particularly in suspected SARS-COV-2 cases to limit the risk for the operators. The high number of bodies to examine and the high risk for operators are the reasons why there is a reduction in the rates of autopsies on SARS-COV-2 infected subjects. Other limitations to approach a full autopsy are the availability of adequate mortuary rooms; the lack of proper PPE and the inadequate training of many operators which is fundamental to reduce the risk of direct and cross contaminations.

In many clinical settings, pulmonary $\mathrm{CT}$ findings are not considered a diagnostic method for COVID-19, this technique is currently used as a screening method, at least until the data of viral analysis of the nose and throat swab are available. The virtual autopsy with PMCT is already applied in cases of subjects with an ascertained diagnosis of SARSCOV-2 infection who died at home [45]. The authors propose the use of these post-mortem investigation techniques in cadavers of ascertained and suspected SARS-COV-2 infected subjects because of:

(1) Its low invasivity (or non-invasivity at all in some cases) that reduce significantly the risk of infection of the operators;

(2) Its capability to extrapolate preliminary information about potential COVID-19 lung disease, particularly in cadavers were pre-death clinical information, and the complete results of the viral nose and throat swab are not available.

(3) Its rapidity and capability do not require particular environmental conditions that are main differences with the techniques normally applicable to living patients.

Moreover, in ascertained cases of death due to COVID-19, eventually, CT guided, post-mortem percutaneous biopsies might improve the understanding of this lethal pathology with an important impact on prevention and treatment and at the same time ensuring a reduction of infection for the operators compared with classical autopsy techniques. This technique produces also an objective database, available for further analysis against unrepeatable autopsy procedure. Due to the aforementioned reasons, the authors propose this technique as an innovative tool to reduce the risks of operators during pandemic emergencies.

\section{CONCLUSIONS}

Emergency management is created to provide methodologies and techniques to face and reduce the risks during adverse events like epidemics. The assessment and measurement of entity level risks is an essential step to make correct decisions about countermeasures. The risk control, together with the relating phase of their evaluation, is the most defining phase of the whole process. The purpose of emergency management actions is, therefore, to help populations and the emergency operators to live with low uncertainty in an environment with high safety and security. Then, the emergency management actions need to be organized to stand up to the innovations that are also being introduced into the scientific world (in terms of new technologies, methods, instruments, education and training programs) and must detect and implement existing techniques used for different applications to improve the emergency response system. Therefore, from the paper it can be evinced that the authors have approached the technological crosscontamination mentality and proposes the application of virtual autopsy techniques in the study of ascertained or suspected SARS-COV-2 infected deceased patients. This method is proposed not only as a screening technique but also as a method of post-mortem investigation. Virtual autopsies are able to provide considerable information on a high number of COVID-19 infected people and with a significant reduction of infection for the operators.

\section{REFERENCES}

[1] Organization WH. (2000). Rolling updates on coronavirus disease (COVID-19). https://wwwwhoint/emergencies/diseases/novelcoronavirus-2019/events-as-theyhappen.

[2] Holmes, K.V. (2003). SARS-associated coronavirus. The New England Journal of Medicine, 348: 1948-1951. https://doi.org/10.1056/NEJMp030078

[3] Su, H., Yang, M., Wan, C., Yi, L.X., Tang, F., Zhu, H.Y., Yi, F., Yang, H.C., Fogo, A.B., Nie, X., Zhang, C. (2020). Renal histopathological analysis of 26 postmortem findings of patients with COVID-19 in China. Kideny International, 98(1): 219-227. https://doi.org/10.1016/j.kint.2020.04.003

[4] Kissling, S., Rotman, S., Gerber, C., Halfon, M., 
Lamoth, F., Comte, D. (2020). Collapsing glomerulopathy in a COVID-19 patient. Kidney International, $98(1)$ : 228-231. https://doi.org/10.1016/j.kint.2020.04.006

[5] Rodriguez-Morales, A.J., Cardona-Ospina, J.A., Gutiérrez-Ocampo, E., Villamizar-Peña, R., HolguinRivera, Y., Escalera-Antezana, J.P., Alvarado-Arnez, LE., Bonilla-Aldana, D.K., Franco-Paredes, C., HenaoMartinez, A.F., Paniz-Mondolfi, A., Lagos-Grisales, G.J., Ramírez-Vallejo, E., Suárez, J.A., Zambrano, L.I., Villamil-Gómez, W.E., Balbin-Ramon, G.J., Rabaan, A.A., Harapan, H., Dhama, K., Nishiura, H., Kataoka, H., Ahmad, T., Sah, R. (2020). Clinical, laboratory and imaging features of COVID-19: A systematic review and meta-analysis. Travel Medicine and Infectious Disease, 34:

101623.

https://doi.org/10.1016/j.tmaid.2020.101623

[6] Menter, T., Haslbauer, J.D., Nienhold, R., Savic, S., Hopfer, H., Deigendesch, N., Frank, S., Turek, D., Willi, N., Pargger, H. (2020). Post-mortem examination of COVID19 patients reveals diffuse alveolar damage with severe capillary congestion and variegated findings of lungs and other organs suggesting vascular dysfunction. Histopathology, $\quad 77(2)$ :

198-209. https://doi.org/10.1111/his.14134

[7] Xu, Z., Shi, L., Wang, Y.J., Zhang, J.Y., Huang, L., Zhang, C. (2020). Pathological findings of COVID-19 associated with acute respiratory distress syndrome. The Lancet Respiratory Medicine, 8(4): 420-422. https://doi.org/10.1016/s2213-2600(20)30076-x

[8] Tian, S.F., Hu, W.D., Niu, L., Liu, H., Xu, H.B., Xiao, S.Y. (2020). Pulmonary pathology of early phase 2019 novel coronavirus (COVID-19) pneumonia in two patients with lung cancer. Journal of Thoracic Oncology, 15(5):

700-704. https://doi.org/10.1016/j.jtho.2020.02.010

[9] Health and Safety Executive Advisory Committee on Dangerous Pathogens. The Approved List of Biological Agents. https://www.hse.gov.uk/pubns/misc208.pdf.

[10] Osborn, M., Lucas, S., Stewart, B., Youd, E. (2020). Autopsy practice relating to possible cases of COVID19 (2019-nCov, novel coronavirus from China 2019/2020) secondary autopsy practice relating to possible cases of COVID-19 (2019-nCov, novel coronavirus from China 2019/2020). Briefing of the Royal College of Pathologists. The Royal College of Pathologists.

[11] Gruppo di Lavoro ISS Cause di morte COVID-19. (2020). Procedura per l'esecuzione di riscontri diagnostici in pazienti deceduti con infezione da SARSCoV-2. Rapporto ISS COVID-19, 27.

[12] Centers for disease control and prevention. Collection and Submission of Postmortem Specimens from Deceased Persons with Known or Suspected COVID-19. https://www.cdc.gov/coronavirus/2019ncov/hcp/guidance-postmortem-specimens.html.

[13] Thali, M.J., Kneubuehl, B.P., Vock, P., Allmen, G.V., Dirnhofer, R. (2002). High-speed documented experimental gunshot to a skull-brain model and radiologic virtual autopsy. The American Journal of Forensic Medicine and Pathology, 23(3): 223-228.

[14] Thali, M.J., Dirnhofer, R. (2004). Forensic radiology in German-speaking area. Forensic Science International, 144(2-3): 233-242. https://doi.org/10.1016/j.forsciint.2004.04.058
[15] Thali, M.J., Yen, K., Schweitzer, W., Vock, P., Boesch, C., Ozdoba, C., Schroth, G., Ith, M., Sonnenschein, M., Doernhoefer, T., Scheurer, E., Plattner, T., Dirnhofer, R. (2003). Virtopsy, a new imaging horizon in forensic pathology: Virtual autopsy by postmortem multislice computed tomography (MSCT) and magnetic resonance imaging (MRI)-a feasibility study. Journal of Forensic Science, 48(2): 386-403.

[16] Filograna, L., Pugliese, L., Muto, M., Tatulli, D. Guglielmi, G., Thali, M.J., Floris, R. (2019). A practical guide to virtual autopsy: Why, when and how. Seminars in Ultrasound, CT and MRI, 40(1): 56-66. https://doi.org/10.1053/j.sult.2018.10.011

[17] Jackowski, C., Sonnenschein, M., Thali, M.J., Aghayev, E., von Allmen, G., Yen, K., Dirnhofer, R., Vock, P. (2005). Virtopsy: Postmortem minimally invasive angiography using cross section techniquesimplementation and preliminary results. Journal of Forensic Science, 50(5): 1175-1186. https://doi.org/10.1520/JFS2005023

[18] Jackowski, C., Bolliger, S., Aghayev, E., Christe, A., Kilchoer, T., Aebi, B., Périnat, T., Dirnhofer, R., Thali, M.J. (2006). Reduction of postmortem angiographyinduced tissue edema by using polyethylene glycol as a contrast agent dissolver. Journal of Forensic Sciences, 51(5): 1134-1137. https://doi.org/10.1111/j.15564029.2006.00207.x

[19] Jackowski, C., Persson, A., Thali, M.J. (2008). Whole body postmortem angiography with a high viscosity contrast agent solution using polyethylene glycol as contrast agent dissolver. Journal of Forensic Science, 53(2): $\quad 465-468 . \quad$ https://doi.org/10.1111/j.15564029.2008.00673.x

[20] Ross, S., Spendlove, D., Bolliger, S., Christe, A., Oesterhelweg, L., Grabherr, S., Thali, M.J., Gygax, E. (2008). Postmortem whole-body CT angiography: Evaluation of two contrast media solutions. American Journal of Roentgenology Diagnostic Imaging and Related Sciences, 190: 1380-1389. https://doi.org/10.2214/AJR.07.3082

[21] Grabherr, S., Doenz, F., Steger, B., Dirnhofer, R. Dominguez, A., Sollberger, B., Gygax, E., Rizzo, E., Chevallier, C., Meuli, R., Mangin, P. (2011). Multiphase post-mortem CT angiography: Development of a standardized protocol. International Journal of Legal Medicine, 125: 791-802. https://doi.org/10.1007/s00414-010-0526-5

[22] Grabherr, S., Heinemann, A., Vogel, H., Rutty, G., Morgan, B., Woźniak, K., Dedouit, F., Fischer, F., Lochner, S., Wittig, H., Guglielmi, G., Eplinius, F., Michaud, K., Palmiere, C., Chevallier, C., Mangin, P., Grimm, J.M. (2018). Postmortem CT angiography compared with autopsy: A forensic multicenter study. Radiology, 288(1): 270-276 https://doi.org/10.1148/radiol.2018170559

[23] Aghayev, E., Thali, M.J., Sonnenschein, M., Jackowski, C., Dirnhofer, R., Vock, P. (2007). Post-mortem tissue sampling using computed tomography guidance. Forensic Science International, 166(2-3): 199-203. https://doi.org/10.1016/j.forsciint.2006.05.035

[24] Aghayev, E., Ebert, L.C., Christe, A., Jackowski, C., Rudolph, T., Kowal, J., Vock, P., Thali, M.J. (2008). CT data-based navigation for post-mortem biopsy-a feasibility study. Journal of Forensic and Legal Medicine, 15(6): 382-387. 
https://doi.org/10.1016/j.jflm.2008.02.007

[25] Bolliger, S.A., Filograna, L., Spendlove, D., Thali, M.J., Dirnhofer, S., Ross, S. (2010). Post-mortem imageguided biopsy as an adjuvant to minimal invasive autopsy with computed tomography and post-mortem angiography: A feasibility study. American Journal of Roentgenology Diagnostic Imaging and Related Sciences, 195(5): 1051-1056. https://www.ajronline.org/doi/full/10.2214/AJR.10.4600

[26] Filograna, L., Bolliger, S.A., Kneubuehl, B., Jackowski, C., Hatch, G.M., Thali, M.J. (2012). A minimally invasive technique for the detection and analysis of pulmonary fat embolism: A feasibility study. Journal of Forensic Science, 57(5): 1329-1335. https://doi.org/10.1111/j.1556-4029.2012.02134.x

[27] Blokker, B.M., Wagensveld, I., Weustink, A.C., Wolter Oosterhuis, J., Hunink, M.G.M. (2016). Non-invasive or minimally invasive autopsy compared to conventional autopsy of suspected natural deaths in adults: A systematic review. European Radiology, 26: 1159-1179. https://doi.org/10.1007/s00330-015-3908-8

[28] Bolliger, S.A., Thali, M.J. (2009). The virtopsy approach (3D optical and radiological scanning and reconstruction in forensic medicine). CRC Press, Taylor \& Francis Group, Boca Raton, USA.

[29] Ibrahim, A.O., Zuki, A.B.M., Noordin, M.M. (2013). Applicability of virtopsy in veterinary practice: A short review. Pertanika Journal of Tropical Agricultural Science, 35(1): 1-8.

[30] Behzad, S., Aghaghazvini, L., Radmard, A.R., Gholamrezanezhad, A. (2020). Extrapulmonary manifestations of COVID-19: Radiologic and clinical overview. Clinical Imaging, 66: 35-41. https://doi.org/10.1016/j.clinimag.2020.05.013

[31] Arabi, Y.M., Arifi, M.A., Balkhy, M.H., Najm, M., Aldwood, M.S., Ghabashi, M. (2014). Clinical course and outcomes of critically ill patients with Middle East respiratory syndrome coronavirus infection. Annals of Internal Medicine, 160(6): 389-397. https://doi.org/10.7326/M13-2486

[32] Gu, J., Gong, E., Zhang, J., Gao, Z., Zhong, Y., Zou, W., Zhan, J., Wang, S., Xie, Z., Zhuang, H., Wu, B.Q., Zhong, H., Shao, H., Fang, W., Gao, D., Pei, F., Li, X., He, Z., Xu, D., Shi, X., Anderson, V.M., Leong, A. (2005). Multiple organ infection and the pathogenesis of SARS. Journal of Experimental Medicine, 202(3): 415424. https://doi.org/10.1084/jem.20050828

[33] China National Health Commission. (2020). Diagnosis and treatment of novel coronavirus pneumonia in China (trial version 7). http://en.nhc.gov.cn/202003/29/c 78469.htm, accessed on 10 May 2020.

[34] Yao, X.H. (2020) A pathological report of three COVID-19 cases by minimally invasive autopsies. Chinese Journal of Pathology, 49: E009. https://doi.org/10.3760/cma.j.cn112151-2020031200193

[35] Chung, M., Bernheim, A., Mei, X.Y., Zhang, N., Zeng, X., Cui, J.F., Xu, W., Yang, Y., Fayad, Z., Jacobi, A., Li, K., Li, S., Shan, H. (2020). CT imaging features of 2019 Novel Coronavirus (2019-nCoV). Radiology, 295: 202207.

[36] Kong, W., Agarwal, P. (2020). Chest imaging appearance of COVID-19 infection. Radiology Cardiothoracic Imaging, 2(1). https://doi.org/10.1148/ryct.2020200028
[37] Bernheim, A., Mei, X.Y., Huang, M.Q., Yang, Y., Fayad, Z.A., Zhang, N., Diao, K.Y., Lin, B., Zhu, X., Li, K., Li, S., Shan, H., Jacobi, Chung, M. (2020). Chest CT findings in Coronavirus Disease-19 (COVID-19): Relationship to duration of infection. Radiology, 295(3): 685-691. https://doi.org/10.1148/radiol.2020200463

[38] Pan, F., Ye, T.H., Sun, P., Gui, S. Liang, B. (2020). Time course of lung changes on chest CT during recovery from 2019 Novel Coronavirus (COVID-19) Pneumonia. Radiology, 295(3): 715-721. https://doi.org/10.1148/radiol.2020200370

[39] Bai, H.X., Hsieh, B., Xiong, Z., Halsey, K., Choi, J.W. (2020). Performance of radiologists in differentiating COVID-19 from viral pneumonia on chest CT. Radiology, 296(2): $\quad$ E46-E54. https://doi.org/10.1148/radiol.2020200823

[40] Salehi, S., Abedi, A., Balakrishnan, S., Gholamrezanezhad, A. (2020). Coronavirus disease 2019 (COVID-19): A systematic review of imaging findings in 919 patients. American Journal of Roentgenology Diagnostic Imaging and Related Sciences, $\quad 215(1)$ : 87-93 https://www.ajronline.org/doi/10.2214/AJR.20.23034

[41] Ai, T., Yang, Z., Hou, H., Zhan, C., Chen, C., Lv, W., Tao, Q., Sun, Z., Xia, L. (2020). Correlation of chest CT and RT-PCR testing in coronavirus disease 2019 (COVID-19) in china: A report of 1014 cases. Radiology, 296(2): E32-E40. https://doi.org/10.1148/radiol.2020200642

[42] Winichakoon, P., Chaiwarith, R., Liwsrisakun, C., Salee, P., Goonna, A., Limsukon, A., Kaewpoowat, Q. (2020). Negative nasopharyngeal and oropharyngeal swab does not rule out COVID-19. Journal of Clinical Microbiology, 58: e00297-20. https://doi.org/10.1128/JCM.00297-20

[43] Filograna, L., Thali, M.J. (2017). Post-mortem CT imaging of the lungs: Pathological versus nonpathological findings. La Radiologia Medica, 122: 902908. https://doi.org/10.1007/s11547-017-0802-2

[44] Filograna, L., Tartaglione, T., Vetrugno, G., Guerra, C., Fileni, A., Bonomo, L. (2015). Freshwater drowning in a child: A case study demonstrating the role of postmortem computed tomography. Medicine, Science and the Law, 55(4): 304-311. https://doi.org/10.1177/0025802414568045

[45] Schweitzer, W., Ruder, T., Baumeister, R., Bolliger, S., Thali, M.J., Meixner, E., Ampanozi, G. (2020). Implications for forensic death investigations from first Swiss post-mortem CT in a case of non-hospital treatment with COVID-19. Forensic Imaging, 21: 200378. https://doi.org/10.1016/j.fri.2020.200378

[46] Albarello, F., Pianura, E., Di Stefano, F., Zumla, A., Ippolito, G. (2020). 2019-novel coronavirus severe adult respiratory distress syndrome in two cases in Italy: An uncommon radiological presentation. International Journal of Infectious Diseases, 93: 192-197. https://doi.org/10.1016/j.ijid.2020.02.043

[47] Salehi, S., Abedi, A., Balakrishnan, S., Gholamrezanezhad, A. (2020). Coronavirus disease 2019 (COVID-19): A systematic review of imaging findings in 919 patients. American Journal of Roentgenology Diagnostic Imaging and Related $\begin{array}{lll}\text { Sciences, } & \text { 215(1): }\end{array}$ https://doi.org/10.2214/AJR.20.23034

[48] Valette, X., du Cheyron, D., Goursaud, S. (2020). 
Mediastinal lymphadenopathy in patients with severe COVID-19. Lancet Infection Disease. https://doi.org/10.1016/S1473-3099(20)30310-8

[49] Alsaad, K.O., et al. (2018). Histopathology of Middle East respiratory syndrome coronovirus (MERS-CoV) infection-clinicopathological and ultrastructural study. Histopathology, 72(3): 516-524. https://doi.org/10.1111/his.13379

[50] Huang, C., Hajeer, A.H., Balwi, M.A., Moaiqel, M.A., Al Oudah, N., Ajlan, A.Z., Aljohani, S., Alsolamy, S. (2020). Clinical features of patients infected with 2019 novel coronavirus in Wuhan, China. The Lancet, 395(10223): 497-506. https://doi.org/10.1016/S01406736(20)30183-5

[51] Baig, A.M., Khaleeq, A., Ali, U., Syeda, H. (2020). Evidence of the COVID-19 virus targeting the CNS: Tissue distribution, host-virus interaction, and proposed neurotropic mechanisms. ACS Chemical Neuroscience, 11(7): https://dx.doi.org/10.1021/acschemneuro.0c00122

[52] Sharifi-Razavi, A., Karimi, N., Rouhani, N. (2020). COVID 19 and intra cerebral hemorrhage: Causative or coincidental. New Microbes and New Infections, 35: 100669. https://doi.org/10.1016/j.nmni.2020.100669

[53] Poyiadji, N., Shahin, G., Noujaim, D., Stone, M., Patel, S., Griffith B. (2020). COVID-19-associated acute hemorrhagic necrotizing encephalopathy: CT and MRI features. Radiology, 296(2): E119-E120 https://doi.org/10.1148/radiol.2020201187

[54] Zhou, F., Yu, T., Du, R.H., Fan, G.H., Liu, Y., Liu, Z.B. (2020). Clinical course and risk factors for mortality of adult inpatients with COVID-19 in Wuhan, China: A retrospective cohort study. The Lancet, 395: 1054-62. https://doi.org/10.1016/S0140-6736(20)30566-3

[55] Varga, Z., Flammer, A.J., Steiger, P., Haberecker, M., Andermatt, R., Zinkernagel, A.S. (2020). Endothelial cell infection and endotheliitis in COVID-19. The Lancet, 395(10234): 1417-1418. https://doi.org/10.1016/S0140-6736(20)30937-5

[56] Klok, F.A., Kruip, M.J.H.A., van der Meer, N.J.M., Arbous, M.S., Gommers, D.A.M.P.J., Kant, K.M., Stals, M.A.M., Huisman, M.V., Endeman, H. (2020). Incidence of thrombotic complications in critically ill
ICU patients with COVID-19. Thrombosis Research, 191:

https://doi.org/10.1016/j.thromres.2020.04.013

[57] Poissy, J., Goutay, J., Caplan, M., Parmentier, E., Duburcq, T., Lassalle, F., Jeanpierre, E., Rauch, A., Labreuche, J., Susen, S. (2020). Pulmonary embolism in COVID-19 patients: Awareness of an increased prevalence. Circulation, 142(2): 184-186. https://doi.org/10.1161/CIRCULATIONAHA.120.0474 30

[58] Leonard-Lorant, I., Delabranche, X., Helms, J., Pauzet, C., Collange, O., Schneider, F., Lbani, A., Bilbault, P., Moliere, S., Leyendecker, P., Roy, C., Ohana, M. (2020) Acute pulmonary embolism in COVID-19 patients on CT angiography and relationship to D-dimer levels. Radiology, 296(3). https://doi.org/10.1148/radiol.2020201561

[59] Turillazzi, E., Frati, P., Pascale, N., Pomara, C., Grilli, G., Viola, R.V., Fineschi, V. (2016). Multi-phase postmortem CT-angiography: A pathologic correlation study on cardiovascular sudden death. Journal of Geriatric Cardiology, $\quad$ 13(10): $855-865$. https://doi.org/10.11909/j.issn.1671-5411.2016.10.003

\section{NOMENCLATURE}

$\begin{array}{ll}\text { MERS } & \text { Middle East Respiratory Syndrome } \\ \text { SARS-COV-2 } & \begin{array}{l}\text { Severe Acute Respiratory Syndrome } \\ \text { COronavirus 2 }\end{array} \\ \text { APR } & \text { Analysis, Prevention, and Response } \\ \text { COVID-19 } & \begin{array}{l}\text { coronavirus disease 2019 } \\ \text { World Health Organization }\end{array} \\ \text { WHE } & \text { Health and Safety Executive's } \\ \text { ACDP } & \text { Advisory Committee on Dangerous } \\ \text { HG } & \text { Pathogens } \\ \text { PPE } & \text { Hazard group } \\ \text { PMCT } & \text { personal protective equipment } \\ \text { CT } & \text { Post-Mortem Computed Tomography } \\ \text { MRI } & \text { Computed Tomography } \\ \text { 3D } & \text { Magnetic Resonance Imaging }\end{array}$

